\title{
Designing Experiments for Children and Robots
}

\author{
Graham Parsonage \\ University of Central \\ Lancashire, \\ Preston, PR1 2HE, UK \\ gparsonage1@uclan.ac.uk \\ Matthew Horton \\ University of Central \\ Lancashire, \\ Preston, PR1 2HE, UK \\ mplhorton@uclan.ac.uk

\section{Janet C. Read} \\ University of Central \\ Lancashire, \\ Preston, PR1 2HE, UK \\ jcread@uclan.ac.uk
}

Permission to make digital or hard copies of part or all of this work for personal or classroom use is granted without fee provided that copies are not made or distributed for profit or commercial advantage and that copies bear this notice and the full citation on the first page. Copyrights for third-party components of this work must be honored. For all other uses, contact the owner/author(s).

IDC '20 Extended Abstracts, June 21-24, 2020, London, United Kingdom (C) 2020 Copyright is held by the owner/author(s).

ACM ISBN 978-1-4503-8020-1/20/06.

https://doi.org/10.1145/3397617.3397841

\begin{abstract}
The way in which a robot is presented to children can have a profound effect on their perception of its capabilities. A Poppy Humanoid robot was introduced to 43 children (aged 7-9) either as a robot that needed programming or as a member of the team which needed to learn. The children were asked to write down three actions they believed that the robot could complete. Thematic analysis was then used to categorise the data. When the robot was not humanised, $71 \%$ of the suggestions were about completing a physical action or sequence of actions and $14 \%$ required the robot to exhibit intelligence or learning. When humanised, $39 \%$ of the actions were physical and 35\% were categorised as intelligent. Introducing the robot as human captured emotional and appearance actions not otherwise present.
\end{abstract}

\section{Author Keywords}

Child-Robot Interaction; Anthropomorphism; Robot; Design; Experimentation; Children

\author{
CSS Concepts \\ - CCS $\rightarrow$ Human-centered computing $\rightarrow$ Human \\ computer interaction (HCI) $\rightarrow$ HCI theory, \\ concepts and models;
}




\section{Introduction}

Robots of all sorts are becoming increasingly prevalent within society. It is predicted that the number of industrial robots will have soon increased to 2.6 million [7] and the growth in humanoid robots will be around $40 \%$ over the next 25 years with opportunities for such robots in defense, shopping and healthcare [8].

One area where robots are increasingly utilised is education. Examples include robots supporting children in early years learning [3], support for children with autism [12] and the general integration of robots into the classroom [2]. This increased positioning of robots alongside children has stimulated the child-robot interaction (cHRI) research.

This paper gives some insights on how children perceive robots whilst also contributing to the wider discussion about how children can effectively participate in robot design. It is intended that the findings help to inform the design of future empirical studies with robots and children.

\section{Related Work}

\section{Child Robot Design}

Belpaeme [1] makes the observes that children have a different perception of robots to adults with a greater tendency to anthropomorphise and ascribe life-like characteristics to them.

From a child-computer interaction perspective, the robotic design space has been described by Woods [14] as being concerned with 4 factors:

- Appearance

- Locomotion
- Gender

- Personality

This schema refers to the robot from its most productlike, through machine-like, agent-like and then humanlike characteristics. Design studies of robots have, over time, followed this in the sense that earliest studies focused on how the robot might look, and more recent studies have considered the more humanlike properties.

Some of the earliest work on children designing robots came from [4] in the PETS project where children worked in small design teams with adults and constructed physical prototypes that demonstrated how robots might look. In later work from the same group, the teams were reconfigured and proceeded to design some of the things the robot might do, moving from appearance to locomotion [10].

Gender has been 'designed into' robots in several studies; in many cases this is where the robot has a humanoid form but some inanimate robots have also been assigned gender [13]. Determining if children are assigning a gender to their designs may be based on how the design looks, how it is dressed, named and presented, or it can be implied from the way the child addresses the robot [5]. Referring to robots as he or she, in English speaking contexts, might suggest the children are giving the robot a gender but in other languages (for example Welsh and French), where there either is no neutral pronoun or where objects can be masculine or feminine, such an interpretation could be flawed. 


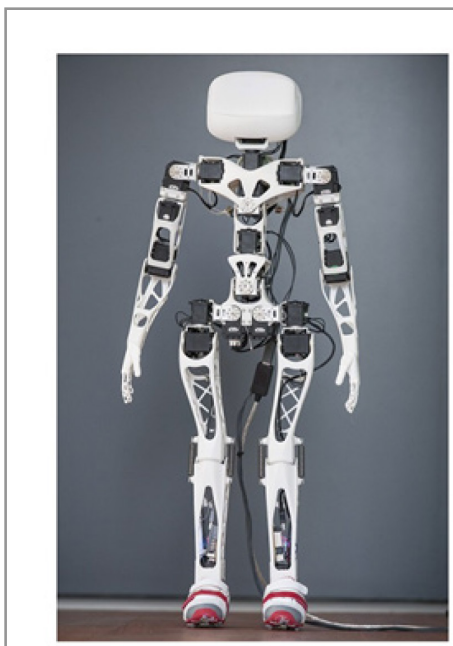

Figure 1: Poppy Humanoid Robot [10]
Designing personalities into robots is a more recent development in CHRI; most of the studies in this space are concerned with emotional design (not strictly studying personality) and this work is encouraged by the many studies that are looking at how robots can be assistive technologies for children $[9,12]$.

Philosophically, there are also questions to be asked about the extent to which children can, and should, participate in robot design. Iivari et al. [6] in their paper on working with children in schools in participatory design sessions ask questions about the way such studies are set up and they specifically question the extent to which children can contribute.

This study examines how the way in which a robot is presented to children affects their perception of its capabilities. The following hypotheses were tested.

$\mathrm{H} 1$ : Introducing the robot as a robot would encourage participants to attribute predominantly physical actions to the robot.

$\mathrm{H} 2$ : Introducing the robot as human would encourage participants to attribute intelligence and emotional characteristics to the robot.

\section{Method}

Participants

Forty-three children were recruited from two local primary schools and attended the University labs by school on two separate occasions over a two-week period. The first group consisted of 8 boys and 20 girls aged 8 to 9 . The second group consisted of 9 boys and 6 girls aged 7 to 8 .

\section{Apparatus}

The robot used in the study was a Poppy Humanoid 3D printed humanoid robot designed to be used by educators, artists and scientists in a variety of medium [11]. In the study the robot was not switched on but presented to the children sitting in a compliant state.

Two almost identical worksheets were prepared for the children to use in the data gathering activity. These were used to gather the ideas from the children as well as to provide a space for drawings of the robot. The worksheets differed only in how they referred to the robot as 'humanoid' or 'robot'.

\section{Procedure}

Before the study, consent was obtained from the children's parents. Additionally, the children were given the opportunity to opt out at any point.

On arrival at the labs, the pupils were split into groups of between 3 and 6 children by their accompanying teachers and they subsequently attended the session in these groups. On entering the room each group was introduced to the Poppy Humanoid in one of two ways. Either the robot was humanised and introduced as a member of the team (humanised condition) or the robot was introduced as a robot which required programming (robot condition). In the first case the children were asked to write down three things Poppy could learn to do. The researcher referred to the robot as she or Poppy. In the second case the Poppy was referred to as a robot which required programming and in this case the children were asked to write down three things the robot could be programmed to do. In both cases the children were asked to draw a picture of the robot doing one of the things they had written down. 


\begin{tabular}{|c|c|}
\hline $\begin{array}{c}\text { Action } \\
\text { Category }\end{array}$ & Description \\
\hline $\begin{array}{l}\text { Action } \\
\text { Focused }\end{array}$ & $\begin{array}{l}\text { Completion of a } \\
\text { physical action } \\
\text { or sequence of } \\
\text { actions such as } \\
\text { walking or } \\
\text { playing football. }\end{array}$ \\
\hline Emotional & $\begin{array}{c}\text { Exhibiting } \\
\text { feelings towards } \\
\text { self or others } \\
\text { such as being } \\
\text { happy or } \\
\text { friendly. }\end{array}$ \\
\hline $\begin{array}{c}\text { Intelligence } \\
\text { and } \\
\text { Learning }\end{array}$ & $\begin{array}{l}\text { Able to initiate } \\
\text { or modify } \\
\text { actions in the } \\
\text { light of ongoing } \\
\text { events such as } \\
\text { driving a car or } \\
\text { learning a } \\
\text { language. }\end{array}$ \\
\hline Assistive & $\begin{array}{l}\text { Give help or } \\
\text { support to carry } \\
\text { out an action or } \\
\text { task such as } \\
\text { cleaning or } \\
\text { helping with } \\
\text { homework }\end{array}$ \\
\hline Organic & $\begin{array}{l}\text { Performing an } \\
\text { action } \\
\text { performed solely } \\
\text { by a living entity } \\
\text { such as } \\
\text { breathing or } \\
\text { dying. }\end{array}$ \\
\hline Appearance & $\begin{array}{c}\text { Make changes to } \\
\text { physical features } \\
\text { such as applying } \\
\text { makeup or doing } \\
\text { hair. }\end{array}$ \\
\hline \multicolumn{2}{|c|}{ Table 1: Action Categories } \\
\hline
\end{tabular}

Each group spent approximately twenty minutes on the task. After the researcher introduced the robot the children were given time to interact with it before completing one of the worksheets. The researcher interacted with the children whilst they completed the worksheet and notes were made on comments the children made whilst completing the task. Twenty-two children completed the humanised worksheet and twenty-one children completed the robot worksheet.

\section{Results}

Thematic analysis was employed to analyse and define themes or action categories from the children's suggestions. Where an action did not fit into an existing category a new action category was created. For each action category created a definition was produced along with two examples to ensure that suggestions were categorised correctly (Table 1 ).

The actions the children suggested were placed into the appropriate category and a count taken. See Table 2 .

\begin{tabular}{|c|c|c|}
\hline \multirow[t]{2}{*}{ Action Category } & \multicolumn{2}{|c|}{ Robot Introduced As } \\
\hline & Human & Robot \\
\hline Action Focussed & 32 & 74 \\
\hline Emotional & 6 & 0 \\
\hline $\begin{array}{c}\text { Intelligence and } \\
\text { Learning }\end{array}$ & 29 & 14 \\
\hline Assistive (A & 12 & 15 \\
\hline Organic & 1 & 1 \\
\hline Appearance & 3 & 0 \\
\hline Totals & 83 & 104 \\
\hline
\end{tabular}

83 individual ideas were generated for the human presentation and 104 for the robot presentation totalling 187 suggestions provided by the children. Where the Poppy Humanoid was presented as human $39 \%$ of the actions the children generated were classed as Action Focused, 35\% were categorised as Intelligence and Learning and $14 \%$ as Assistive. Where the Poppy Humanoid was presented as a robot $71 \%$ of the actions generated were Action Focused, 14\% Intelligence and Learning and 14\% Assistive. The Emotional and Appearance categories were unique to the human presentation. The Organic category had 1 suggestion per presentation.

\section{Data Trends}

The first three actions suggested by each child were organized into action categories in the order they were suggested.

Graphs were then produced to identify trends in the data. Figure 2 suggests that the children were more likely to select an action categorised as requiring intelligence and learning as their first choice when the robot was introduced using the human condition. When the robot was introduced using the robot condition the children were more likely to suggest an action categorised as action focussed. This adds further support to both hypotheses.

How the Children Referred to the Robot

Table 3 shows the terms the children used to refer to the robot and indicates that children were more likely to attribute gender to the robot when it had been presented using the human condition. Most of the children who ascribed gender to the robot referred to it as she rather than he. This is unsurprising as both the 


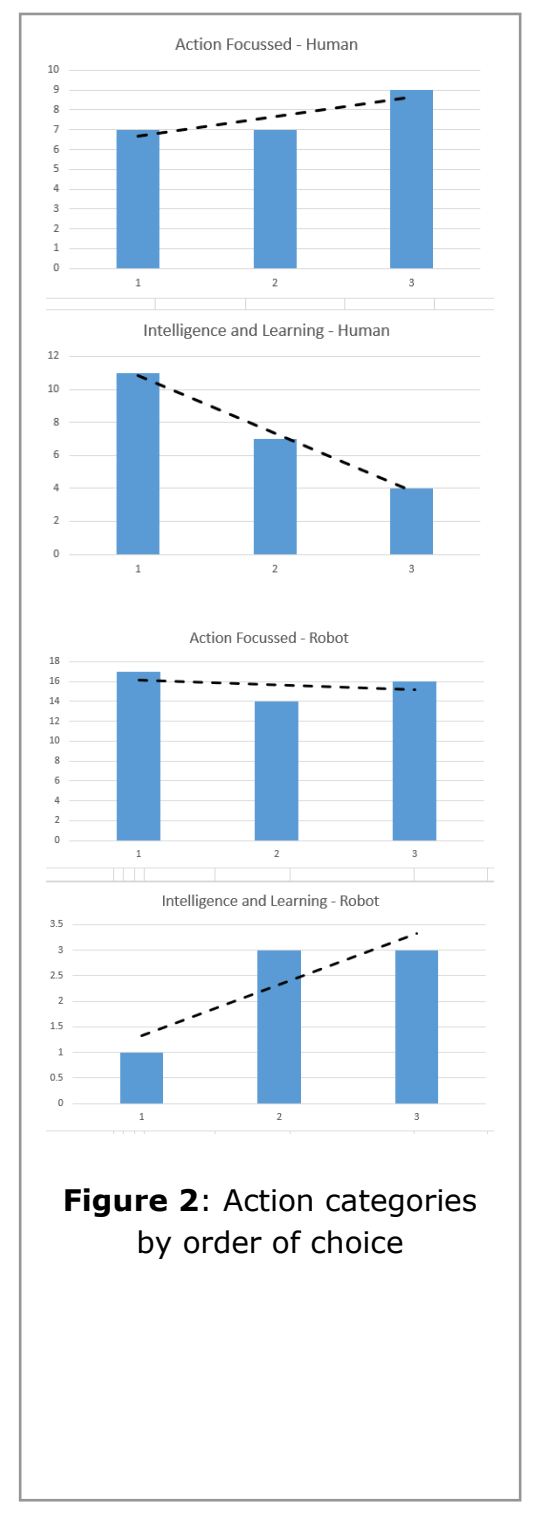

researcher and humanised worksheet referred to Poppy as she. Poppy is also considered a female name in western society.

\begin{tabular}{|c|c|c|c|c|c|c|}
\hline $\begin{array}{l}\text { Presentation } \\
\text { Method }\end{array}$ & $\rightleftarrows$ & $\underset{\frac{\dot{d}}{\mathbf{n}}}{\stackrel{0}{\mathbf{1}}}$ & 文 & 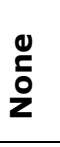 & 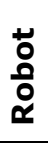 & $\begin{array}{l}\frac{n}{N} \\
\stackrel{+}{0} \\
\stackrel{0}{b}\end{array}$ \\
\hline Human & 1 & 8 & 2 & 11 & 0 & 22 \\
\hline Robot & 2 & 2 & 3 & 13 & 1 & 21 \\
\hline
\end{tabular}

Table 3: How the Children Referred to the Robot

Two action categories (see Figure 3), emotional and appearance were only captured when the Poppy Humanoid was presented as human. The remaining action categories were common to both groups. The presence of these additional categories is indicative that children's perceptions are influenced by the introductory method employed.

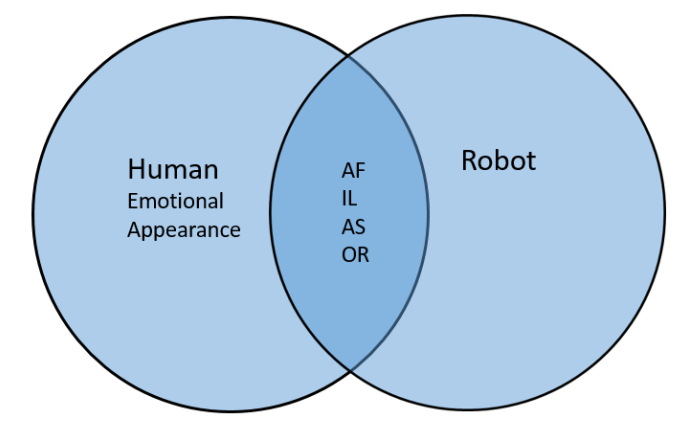

AF (Action Focussed), IL (Intelligence \& Learning), AS, (Assistive), OR (Organic)

Figure 3: Unique Action Categories when the Robot is Presented as Human

\section{Discussion}

The findings from the study suggest that the initial hypotheses presented are correct. When the robot was introduced using the robot condition, $71 \%$ of suggestions the children made were categorised as requiring completion of a physical action. Only $14 \%$ of children suggesting an action that required intelligence and learning and there were 0 suggestions in the emotional category. When the robot was introduced using the human condition, the number of suggestions for a physical action fell to $39 \%$ whilst suggestions for actions requiring intelligence and learning increased to $35 \%$ with $7 \%$ of suggestions categorised as emotional.

It was unsurprising that the use of a humanoid robot elicited suggestions for physical actions associated with human behaviour. The physical design of the robot provides clues to its persona and colours the child's perceptions of what it can achieve. This in conjunction with the child's personal experience produced a rich range of suggested activities. A child who had to use a wheelchair suggested the robot could help people in wheelchairs whilst children who enjoyed gymnastics suggested gymnastic related activities.

\section{Conclusion}

The main findings from this paper are that when introducing a robot to children in a design session, the way the robot is introduced will have an impact on what the children offer in terms of requirements or ideas. With class sized studies, children working in groups, and the possibility that they might 'copy' or 'share' ideas is not likely to have much of an impact on the ideas or requirements generated. 


\section{Limitations \& Future Work}

The findings have limitations. The number of participants is small and a larger sample would add weight to the findings. The study highlights global trends and further work is required to identify the root causes of the trend. It is assumed that the participants attributed characteristics to the robot based on the researchers' actions however the participants' views were not established prior to the study.

Further work will include a replication of the study with older children. We also plan to assess whether replacing the humanoid robot with a non-humanoid robot will affect the hypotheses.

\section{References}

[1] Tony Belpaeme, Paul Baxter, Joachim de Greeff, James Kennedy, Robin Read, Rosemarijn Looije, Mark Neerincx, Ilaria Baroni, and Mattia Coti Zelati. 2013. (eds) Social Robotics. ICSR 2013. Lecture Notes in Computer Science, vol 8239. Springer, Cham

[2] Bernadette Mary Byrne, Alessandra Rossi, and Martina Doolan. 2017. Humanoid Robots Attending Lectures: Research Informed Teaching. In Proceedings of ICETC 2017, 7-11.

[3] Helen Crompton, Kristen Gregory, and Diane Burke. 2018. Humanoid robots supporting children's learning in an early childhood setting. British Journal of Educational Technology 49, 5, 911-927.

[4] Allison Druin, Jamie Montemayor, Jim Hendler, Britt McAlister, Angela Boltman, Eric Fiterman, Aurelie Plaisant, Alex Kruskal, Hanne Olsen, Isabella Revett, Thomas Plaisant Schwenn, Lauren Sumida, and Rebecca Wagner. 1999. Designing PETS: a personal electronic teller of stories. In Proc of CHI 1999, 326-329.

[5] Friederike Eyssel, Dieta Kuchenbrandt, Simon Bobinger, Laura de Ruiter, and Frank Hegel. 2012. 'If you sound like me, you must be more human': on the interplay of robot and user features on human-robot acceptance and anthropomorphism. In Proceedings of HRI 2012. 125-126.

[6] Netta Iivari and Marianne Kinnula. 2016. Inclusive or Inflexible: a Critical Analysis of the School Context in Supporting Children's Genuine Participation. In Proceedings of NordiCHI 2016. Article 63, 10 pages.

[7] International Federation of Robotics. World Robotics Report 2016. Retrieved August 19, 2018 from https://ifr.org/IFR-PRESS-

RELEASES/NEWS/WORLD-ROBOTICS-REPORT2016
[8] Ross Mead, Daniel H. Grollman, Angelica Lim, Cynthia Yeung, Andrew Stout, and W. Brad Knox. 2018. HRI 2018 Workshop: Social Robots in the Wild. In Companion of the 2018 ACM/IEEE HRI 2018, 399-400.

[9] Marti Patrizia, Moderini Claudio, Giusti Leonardo, and Pollini Alessandro. 2009. A robotic toy for children with special needs: From requirements) to design. In IEEE International Conference on Rehabilitation Robotics (ICORR 2009), 918-923.

[10] Catherine Plaisant, Allison Druin, Corinna Lathan, Kapil Dakhane, Kris Edwards, Jack Maxwell Vice, and Jaime Montemayor. 2000. A storytelling robot for pediatric rehabilitation. In Proceedings of the Assets 2000, 50-55.

[11] Poppy Project. Open Source Platform for the Creation, Use and Sharing of Interactive 3D Printed Robots. 2018. Retrieved September 5, 2018 from https://www.poppy-project.org/en/

[12] Ben Robins, Kerstin Dautenhahn, R. Te Boekhorst, and Aude Billard. 2005. Robotic assistants in therapy and education of children with autism: can a small humanoid robot help encourage social interaction skills?. Universal Access in the Information Society 4, 2, 105-120.

[13] Michael L Walters, Dag Sverre Syrdal, Kheng Lee Koay, Kerstin Dautenhahn, and R. Te Boekhorst. 2008 Human approach distances to a mechanicallooking robot with different robot voice styles. In Robot and Human Interactive Communication 2008. RO-MAN 2008. 707-712. IEEE, 2008.

[14] Sarah Woods. 2006. Exploring the design space of robots: Children's perspectives. Interacting with Computers 18, 6: 1390-1418. 